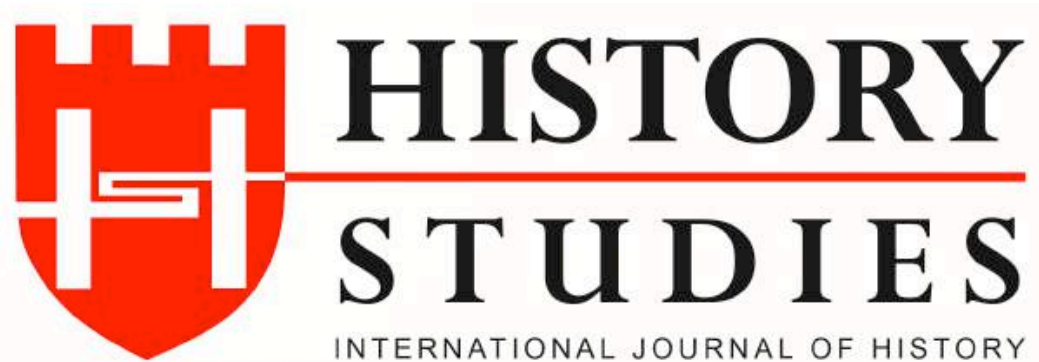

\author{
ISSN: 13094173 (Online) 1309 - 4688 (Print) \\ Volume 12 Issue 1, February 2020 \\ DOI Number: 10.9737/hist.2020.823 \\ Araştırma Makalesi
}

Makalenin Geliş Tarihi: 06.12.2019 Kabul Tarihi: 13.01.2020

Atıf Künyesi: Süleyman Cevat Çevrimli - Hasan Şehmuz Haştemoğlu, “Geleneksel Osmanlı Çarşısı

Örneği, Isparta Üzüm Pazar1”, History Studies, 12/1, Şubat 2020, s. 125-145.

\title{
Geleneksel Osmanlı Çarşısı Örneği, Isparta Üzüm Pazarı
}

\author{
Traditional Ottoman Bazaars, Isparta Üzüm Pazarı \\ Süleyman Cevat Çevrimli - Dr. Hasan Şehmuz Haştemoğlu \\ ORCID No: 0000-0002-2875-773X / 0000-0002-8818-6174 \\ Isparta Süleyman Demirel Üniversitesi
}

$\ddot{0} \mathbf{z}$

Volume 12

Issue 1

February 2020
Yüzyıllardır değişim geçiren ticaret kültürü günümüzde yeni bir boyut kazanmıştır. Selçuklular döneminden başlayarak Osmanlı döneminde gelişen geleneksel Türk çarşı kültürü erozyona uğrayarak yerini alış veriş merkezlerine bırakmıştır. Temelde alış veriş merkezlerinin atası ve Türkİslam Şehircilik kültüründe kentin temel unsurlarından biri kabul edilen geleneksel çarşılar kentin cazibe merkezi konumundan, kent merkezinin sorunlu alanları şekline dönüşmüştür. Bu kentsel mekanlar çevrelerinde üretilen yeni projelerle sürekli baskı altında kalırken, geleneksel çarşı kültürü de beraberinde kaybolmaktadır. Isparta Üzüm Pazarı bu bağlamda Osmanlı Coğrafyasının pek çok kentinde görülebilen bir dönüşüm yaşamaktadır. Öyle ki, koruma altına alınarak kaybolması engellenen alanda tarihi dokunun ve yapıların korunumu sağlanamamaktadır. Yazınsal literatürde hak ettiği değeri bulamayan, hakkında hiçbir arșiv ve belgeleme çalışmasına ulaşılamayan Üzüm Çarşısı için bütüncül bir koruma-kullanma yaklaşımı da geliştirilememiştir. Bu nedenle çalışmada öncelikle literatür ve arşiv çalışması ile çarşının tarihsel gelişimi tespit edilmiştir. Ardından alan çalışması ile tüm çarşının rölövesi alınmış, çarşının mevcut durumu belgelenmiş̧ir. Öyle ki, bu yolla kent merkezinde bulunan tarihi çarşının el halısı ve gülüyle ünlü kente, turizme yönelik proje çalışmaları yapılarak önemli bir ekonomik katkı sağlayabileceği öngörülmüştür. Bu hedefle çarşının mevcut sorunları net biçimde ortaya çıkarılırken, diğer taraftan literatürde gerekli önemi görememiş tarihi çarşının belgelenmesi ve gelecekte yapılacak çalışmalara altlık hazırlanması hedeflenmiştir.

Anahtar Kelimeler: Geleneksel Osmanlı Çarşıları, Ticaret Yapıları, Isparta, Üzüm Pazarı

\section{Abstract}

Trade culture, which has been changing for centuries, has gained a new dimension nowadays. Starting from the Seljuk period, the traditional Turkish bazaar culture that developed during the Ottoman period suffered erosion and left its place to shopping centers. Traditional bazaars, which are considered as the predecessors of shopping centers and one of the basic elements of the city in Turkish-Islamic Urbanism culture, have transformed from the attraction centers to the problematic areas of the city center. While these urban spaces are under constant pressure with new projects produced around them, the traditional bazaar culture is also lost. In this context, Isparta Üzüm Pazarı is undergoing a transformation that can be seen in many cities of the Ottoman Geography. So much so that the protection of the historical texture and structures cannot be ensured in the area that has been taken under protection and prevented from disappearing. A holistic conservation-use approach could 
not be developed for the Üzüm Pazarı, which could not find the value it deserves in the literature, and about which no archive and documentation studies are available. For this reason, the historical development of the marketplace was firstly determined by literature and archive studies. Afterward, with field studies, the survey of the whole marketplace was obtained, and the current status of the marketplace was documented. In this way, it is predicted that the historic marketplace in the city center can make an important economic contribution to the city, which is famous for its handmade rugs and roses, by carrying out project studies for tourism. Together with this objective, while the current problems of the marketplace are clearly revealed, it is aimed to document the historic marketplace, which has not seen the necessary importance in the literature, and to prepare the basis for future studies.

Keywords: Traditional Ottoman Bazaars, Commercial Buildings,Isparta, Üzüm Pazarı

\section{Giriş}

Kent, insanın hayatını düzenlemek üzere meydana getirdiği en önemli, en büyük fiziki ürünü ve insan hayatını yönelten, çevreleyen yapıdır. Toplumsal hayata, insanlar arasındaki ilişkilere biçim veren, sosyal mesafelerin en aza indiği, bu ilişkilerin büyük yoğunluk kazandığı yerdir. Kentin ilk yapı taşı kuşkusuz insan barınma zaruretinin bir ürünü olan evdir. Ancak, insan hayatını idame ettirmek için ihtiyacı olan maddeleri, bunların çeşitlerini üretmek ve bu ürettiklerinin başkalarının ürettikleri ile değiştirmek, satmak, satın almak ve benzeri ile oluşan iktisadi hayat da kentlerin asli bir fonksiyonudur. ${ }^{1}$ Çarşılar, üretim veya ticaret yapmak için dükkânına gelen esnaf ile üretiminin fazlasını paraya çevirmiş veya çevirmek isteyen müşterileri ihtiyaçlarını karşılamak üzere bir araya getiren yerdir. Anadolu coğrafyasında da antikçağdan günümüze agora, pazar, çarşı gibi kavramlarla ticari hayatın, kentlerin oluşumu ve gelişiminde başrol oynadığı görülür. Örneğin eski Helen kentlerinde ilkel agora ya da bir bölümünün, satış tezgâhlarıyla pazara dönüştüğü, 5. yüzyıldan sonra ise ticaretin gelişmesiyle agora yakınında sıra dükkânlar inşa edilmeye başlandığı, kimi örneklerde sıra dükkânların önüne sütunlu bir cephe mimarisi eklendiği görülür. ${ }^{2}$

1071'den sonra Türklerin Anadolu Bizans kentlerine yerleşmeleriyle Türk asker ve beyleri kentlerde askeri kimliklerini kaybederek kentlerin zengin ve nüfuzlu aileleri durumuna gelmişlerdir. Anadolu'ya gelen Türkmenlerin kent hayatına alışmalarında Rum Hıristiyan ahali ile kent pazarlarında alışverişe girişmiş bulunmaları önemli bir etkendir. Çok sayıda Türkmen kentlerde alışverişe ve üretim faaliyetine katılmıştır. ${ }^{3}$ Bu dönemden sonra Anadolu'da ticaret yollarına ve limanlara sahip kentler hızla gelişmiştir. Ancak yeterli belgeleme çalışmalarının bulunmaması ve savaşlar, depremler, yangınlar gibi nedenlerle mevcut belgelerin büyük bölümü de günümüze ulaşamamıştır. Bu nedenle Anadolu'da Selçuklu kentlerinde ticari hayata ilişkin kesin bilgilere ulaşmak mümkün değildir. Diğer taraftan yapılan çalışmalarda Selçuklularda büyük çoğunluğu Arapça ve Farsça 250'ye yakın meslek unvanı tespit edilmiştir. Yabancı araştırmacıların aksine zanaatkârların ve ticaret erbabının büyük çoğunlu gayri Müslim değil Türk veya Müslümanlardan oluştuğu görülmüştür. ${ }^{4} 8$. yüzyıl gelindiğinde

\footnotetext{
${ }^{1}$ Turgut Cansever, İslam'da Şehir ve Mimari, İz Yayıncılık, İstanbul 1997, s.22.

2 R.E.Wycherley, Antik Çăgda Kentler Nasıl Kuruldu?, Çev: Nur Nirven-Nezih Başgelen, Arkeoloji ve Sanat Yayınları, İstanbul 1993, s.46.

${ }^{3}$ Mustafa Akdağ, Türkiye'nin İktisadi ve İçtimai Tarihi, Cem Yayınevi, İstanbul 1995, s.12-13.

${ }^{4}$ Erdoğan Merçil, Türkiye Selçuklularında Meslekler, Türk Tarih Kurumu Yayınları, Ankara 2000, s.194-196.
} 
Anadolu'da ticaret, kısa süren pazarlar ile daha uzun süre devam eden panayırlarda yapılmaktadır. Pazarlar da, panayırlar da devletin himayesi ve kontrolü altındadır. Ayni ve nakdi mübadelenin her ikisi de mevcutken Devlet belirli bir vergi almaktadır. ${ }^{5}$ Osmanlı Devletinin kuruluşu ve yükselme dönemiyle birlikte gelen refah ve zenginlikle ticaretin artması, kentlerin büyümesi, Osmanlı coğrafyasında gerçek anlamda bir çarşı kültürünün ortaya çıkmasına neden olmuştur. Öyle ki bugün mevcut belgelerin ve korunan yapı stokunun büyük bölümü de Osmanlı arşivleri ve Osmanlı Dönemi mimari eserleridir. Eldeki belgelerden kentlerdeki ekonomik etkinliklerin, özellikle ticaretin hacmine ilişkin sayılar konusunda mukataa hesapları kaynak alınırken, anlatım türü kaynaklar oldukça sınırlıdır. Evliya Çelebi ve Kâtip Çelebi'nin coğrafi betimlemeleri bazı kentlerde üretilen özel ürünler konusunda bilgi vermekte ve genellikle kamu binalarının genel dökümlerini içermektedir. ${ }^{6}$

\section{Osmanlı Coğrafyasında Çarşılar}

Osmanlı kentlerinin toplumsal yapısına bakıldığında, nüfusu toplumsal faaliyetleri ve statüleri açısından çeşitli kesimlere ayırmak mümkündür. Bu açıdan Osmanlı kentinde ayaneşraf, memur ve tüccar-esnaf olmak üzere üç ana zümre görülür. Bu sıralama aynı zamanda toplumsal açıdan bir statü derecelemesi kabul edilebilir. Benzer şekilde pek çok kaynak Osmanlı kentini belirleyen üç temel unsuru cami, medrese ve çarşı olarak sıralar. ${ }^{7}$ Osmanlı' da esnaf, şehir ve kasabalarda, mal ve hizmet üretimi yapan iş kollarının belirli bir alanında uzmanlaşmış olanlarının meydana getirdiği mesleki örgütlenmelerdir. ${ }^{8}$ Caminin görülür, medresenin erişilir ve çarşının güvenlikli yerde olması esastır. Bu nedenle bu yapı gruplarını bünyesinde barındıran Külliyeler Osmanlı kenti için son derece önemlidir. "Külliye standart bir birim elemana dayanan yapı tipi ile saflaşmaya dayanan bir kalıp tipi üzerinde gelişen, sınırsız plan ve kompozisyona sahip bir modeldir". ${ }^{9}$ Bu tanımdan yola çıkarak Osmanlı kentinin külliye etrafında oluştuğu, çarşı, bedesten, kervansaray ve hanın külliyenin bir parçası olduğu sonucuna ulaşılabilir. ${ }^{10}$ Ancak külliyelerde bulunan binaları değerlendirirken hayır binaları ile vakıf amacını gerçekleştirmek için yaptırılan akar niteliğindeki binaları aynı kefeye koymamak gerekir.

Diğer bir deyişle kurduğu vakfa gelir sağlamak için kurucusunca yaptırılan han, kapan, dükkan, mahzen, fırın, mumhane, değirmen gibi binalar külliyenin temel binaları arasında sayılmazlar. ${ }^{11}$

Sonuç olarak Selçukluların gelişigüzel görünen çarşısının aksine Osmanlılarda kent alanının \%6-10'unu büyüklüğündeki çarşı yerleşkesinin belirgin bir modeli vardır. ${ }^{12}$ Bu fiziki modelin

\footnotetext{
${ }_{6}^{5}$ M. Fuad Köprülü, Osmanlı Imparatorluğu'nun Kuruluşu, Akçă̆ Yayınları, Ankara 2009, s.88-89.

${ }^{6}$ Suraiya Faroqhi, Osmanlı'da Kentler ve Kentliler, Çev: Neyyir Kalaycıŏ̆lu, Tarih Vakfı Yurt Yayınları, İstanbul 2000, s.69

${ }_{8}^{7}$ Ayşen Şatıroğlu, Oya Okan, Çarşı-Esnaf Kapalıçarşı, İstanbul Ticaret Odası Yayınları, İstanbul 2010, s.33.

8 Mehmet Genç, Osmanlı Esnafı ve Devlet, Osmanlı Imparatorluğunda Çevre ve Şehir, Çevre ve Şehircilik Bakanlığı Yayınları, İstanbul 2015, s.287.

${ }^{9}$ Alpaslan Ataman, Bir Göz Yapıdan Külliyeye, Mimarlar Tasarım Yayınları, İstanbul 2000, s.171.

${ }^{10}$ Kenan Mortan-Önder Küçükerman, Çarşı, Pazar, Ticaret ve Kapalıçarşı, Türkiye İş Bankası Kültür Yayınları, İstanbul 2007. s.69.

${ }_{11}$ Zeynep Ahunbay-Deniz Mazlum-Kemal Eyüpgiller, Prof. Doğan Kuban'a Armă̆an, Osmanlı Külliyelerinde Yerleşme Düzeni: Bir Tipoloji Denemesi, Eren Yayıncılık, İstanbul 1996, s.39-44.
} 
oluşmasında en önemli etkenler ise İslam kültürü ve çoğu kez İslam kültürü ile ilişkili esnaf kültürüdür.

İnsanlık tarihi boyunca pek çok kent planlamasında önemli mabetlerle birlikte çarşılar genellikle şehir merkezindedir. Burada mabetlerin kent halkını çekici bir rol oynaması önemli bir etkendir. Ancak İslam kentlerinde içtimai hayatın yegane odak noktasını kent merkezinde yükselen caminin teşkil etmesi, Müslümanlarında ticari faaliyetlerde İslami kaideleri ön planda tutması, İslam kentlerinde mabet-çarşı beraberliğini daha belirgin kılmıştır. ${ }^{13}$ Öyle ki, 8. yüzyıldan itibaren Orta Doğu ve Kuzey Afrika'da İslam kentlerinde görülmeye başlanan esnaf birliklerinin meydana getirdiği fütüvvet geleneklerine uygun biçimde, dini törenler ve toplu ibadetle ticaretin başlatılması, esnaftan dindarlık ve dürüstlük normlarına uymalarının istemesi ${ }^{14}$ ayrıca Cuma namazı kılınacak (hutbe okunacak minber bulunan) cami sayısının çok kısıtlı oluşu ve genellikle kent merkezinde bulunması cami-çarşı ilişkisini güçlendirmiştir.

Ayrıca İslam kentlerinde çarşılarda ticari faaliyetin yoğunlaştığı bölgelerle ikamet bölgeleri arasında mahremiyet kaygılarıyla kesin bir ayrım mevcuttur. Bu nedenlerle pek çok araştırmacı İslam kentlerinin yegâne karakteristik özelliği olarak çarşıyı göstermiştir. ${ }^{15}$ Osmanlı şehircilik anlayışının cami-çarşı birlikteliğinin önemi fetihle elde edilen şehirlerde çok daha net anlaşılır. Örneğin Osmanlılar Balkanlarda Üsküp'ü 1392 'de fethettikten sonra şehri İslam kültürü kaynaklı Osmanlı şehircilik anlayışı ilkelerine göre yeniden yapılandırmıştır. Bu ilkelere uygun olarak, Osmanlı Üsküp'te üç ana kentsel bölge oluşmuştur. Bunlar kent merkezinde ana Camiçarşı, çarşı1'ya bitişik kale ve kent merkezini çevreleyen mahallelerdir. ${ }^{16}$

Bir diğer örnekte Osmanlıların Orta Doğu'da Şam'ı 1516'da fethinin ardından devlet kapsamlı yapı faaliyetleriyle kendini göstermiştir. Kısa süre içinde Osmanlı şehir merkezi, şehrin batı kısmında büyümüş, kale surlarının dış tarafında camiler, hamamlar ve saraylar inşa edilmiştir. Ayrıca Osmanlıya entegrasyon ve Şam'ın hac güzergahındaki yeri, şehirde ekonomik patlamayı tetiklemiş̧ir.

Daha erken hanedanları ticaret merkezi şehrin çekirdeğinin güney ve doğusunda, Emevi Cami yakınında kurmasına rağmen 16. yılın ikinci yarısında şehrin ticari merkezi surların içinde Emevi Camisinin güney batı tarafında yeni kentsel bölgeye doğru kaymıştır. ${ }^{17}$ Her iki örnekte görüldüğg̈ gibi cami-çarşı bağlantısı son derece güçlüdür. Selçuklulardan sonra Osmanlılarda da İslam geleneğinin devamı olarak, ticaret merkezleri cami-çarşı eksenin de kurulmuştur. ${ }^{18}$ Diğer taraftan gerek Selçuklu gerek Beylikler gerekse Osmanlı şehrinde

\footnotetext{
${ }^{12}$ Kenan Mortan-Önder Küçükerman, Çarşı, Pazar, Ticaret ve Kapalıçarşı, Türkiye İş Bankası Kültür Yayınları, İstanbul 2007. s.108.

${ }^{13}$ Yılmaz Can, Íslam Şehirlerinin Fiziki Yapısı (VII. ve IX. Yüzyıl), Türkiye Diyanet Vakfı Yayınları, Ankara 1995, s.123

${ }^{14}$ Timur Kuran, Islamic Influences on The Ottoman Guilds, The Great Ottoman-Turkish Civilisation Vol.2 Economy and Society, Ed. Kemal Çiçek, Yeni Türkiye Yayınları, Ankara 2000, s.43-59.

${ }^{15}$ Yilmaz Can, age. S.128

16 Aleksandra Krstikj- Hisako Koura, "Identıfyıng The Significance Of Historıc Place in Scopje's Old Bazaar", Journal of Architecture and Planning (Transactions of AIJ) · April 2013, Vol. 78, No. 686, p. 829-835

${ }^{17}$ Stefan Weber, "The Transformation of an Arab-Ottoman Institution The Suq (Bazar) of Damascus from the 16th to the 20th Century", 7 Centuries of Ottoman Architecture A Supra - National Heritage,Yem Yayınları, Istanbul 1999. s.244-253

${ }^{18}$ Neşe Olcaytu, Yaşayan Çarşılar, Novartis Kültür Yayınları, No: 17, İstanbul 2005.
} 
merkezin tek işlevinin neredeyse ticarete indirgenmiş oluşu vakıf kurucuların hizmetleri dağıtamamasına bağlanabilir. Öyle ki, kamusal hizmetler optimum koşullarda sunulabileceği yere değil gereksinenlerin ayağına götürülmüş, sadece işlevler merkezileşebilmiştir. Çünkü vakıf sahipleri dükkan vs. gibi yapıların merkezde olmadıkları takdirde işlemeyeceklerini fark etmişlerdir. ${ }^{19}$

Sonuç olarak, Osmanlı çarşı-pazarları, bedesten veya ulu caminin oluşturduğu bir merkez etrafında gelişmiştir. Bu merkezin çevresindeki birinci kuşak genellikle yerel ve yabancı tüccarlara hizmet veren çarşı-pazarlardan oluşmaktadır. Yine bu kuşakta tamamlayıcı bir unsur olarak ticaret fonksiyonu dışında konaklama hizmeti veren birçok han ile kişisel hizmetler sunan hamam, kıraathane ve berber dükkânları yer almaktadır. ${ }^{20} 16$. yüzyılda belirginleşen geleneksel Osmanlı çarşılarının fiziki yapısı büyük ölçüde şekillenmiş, zaman içerisinde dükkandan kapalı çarşılara kadar geniş bir tipolojiye ulaşmıştır.

\subsection{Geleneksel Osmanlı Ticaret Yapıları}

Aslında Osmanlıda ticaretin kalbi çarşıların kelime anlamı Farsça Cıhar-Suk (dört sokak) terkibinden bozulmuş alış veriş etmeye elverişli, iki tarafı dükkân, üstü örtülü veya açık sokak veya meydanlara verilen isimdir. Osmanlı şehrinde üç tip çarşıdan söz etmek mümkündür. ${ }^{21}$

- Üstü Açık Çarşı1lar

- Kapalı Çarşılar

- Bedestenler

Anadolu kentlerinde üstü açık sokak biçimindeki ticari dokulara genellikle arasta dendiği görülür. Ancak arasta tabirinin Farsçada süslemek manasında "aresten" kelimesinden geldiği bazı kaynaklarda yazmakta ise de, "arasta" sözünün pazar ve çarşı manasında kullanıldığ1 ve "aratsak" tabirinin örtü manasına geldiği bu nedenle arastanın üstü örtülü çarşı anlamında kullanıldığı anlaşılmaktadır. ${ }^{22}$ Arastalar Ortaçağdan modern zamanlara kadar çok az değişikliğe uğramıştır. Dükkanlar ahşap kepenklerle kapatılan açıldığında kepengin alt kısmı tezgah üst kısmı sundurma olan sokak seviyesinden biraz yüksek yapılardır. ${ }^{23}$ Çarşıda ticari hayatın fiziki anlamdaki en küçük birimi dükkânlardır. 2-4m arasında değişen cephe genişliğine sahip, sadece satıcının bulunduğu, müşterinin içeri giremediği, ürünlerin dükkanın önünde ahşap peykeler üzerinde sergilediği birimlerdir. Önlerinde genellikle 5-7m arasında dar sokaklar bulunur. Kent çarşılarında her esnaf kesiminin geleneğine, çalışma ve gedik düzenine göre organize olan bir veya birkaç sokağı sağlı sollu işgal eden, aynı üretimin yapıldığı veya aynı türden malların

\footnotetext{
${ }^{19}$ Uğur Tanyeli, Anadolu-Türk Kentinde Fiziksel Yapının Evrim Süreci (11.-15. yy),( İstanbul Teknik Üniversitesi Fen Bilimleri Enstitüsü Basılı Doktora Tezi), İstanbul 1987, s.182.

${ }^{20}$ M. Sait Şahinalp-Veyis Günal, "Osmanlı Şehircilik Kültüründe Çarşı Sisteminin Lokasyon ve Çarş1 İçi Kademelenme Yönünden Mekânsal Analizi”, Millî Folklor, 2012, Y11 24, Say1 93, s165.

${ }^{21}$ Gündüz Özdeş, Türk Çarşıları, Tepe Yayınları, Ankara 1998, s.7

${ }^{22}$ Burcu Küçükkömürcü, Geleneksel Türk Osmanlı Çarsı Yapıları ve Günümüzdeki Alışveriş Merkezleri Üzerine Bir Inceleme, (Mimar Sinan Güzel Sanatlar Üniversitesi Fen Bilimleri Enstitüsü, Yüksek Lisans Tezi), İstanbul 2005, s.173-178

${ }^{23}$ Yılmaz Can, İslam Şehirlerinin Fiziki Yapısı (VII. ve IX. Yüzyıl), Türkiye Diyanet Vakfı Yayınları/169, Ankara 1995, s.133.
} 
satıldığ işyerleri kurulurken $^{24}$ dikkat çeken nokta arastaların kavaflar arastası, bakırcılar arastası gibi belirli iş ve meslek kollarına ayrışmış olmasıdır. İş kollarının çarşılarda dağılımını etkileyen çeşitli faktörlerden güvenlik de önemli bir endişe kaynă̆ıdır. $\mathrm{Bu}$ nedenle kuyumcuların alanları, en iyi güvenliği sağlamak için kentin merkez bölgelerindeki cuma camisine yakın stratejik bir konumdadır. Pazarlar diğer yandan daha az merkez alanlarda, konut alanlarına daha yakın konumda bulunurlar. İşin uyumluluğu bir başka etkileyici unsurdur. Tahıl ve baharat eşyasını seven bazı el sanatları daha yakın bir yerde bulunurken, demirci ve ilaççı gibi daha az uyumlu esnaflar ayrı alanlara yerleştirilir. ${ }^{25}$

Doğal koşullardan korunmak amacıyla üstü örtülü çarşı yapıları olarak tanımlanabilen Kapalıçarşılardan günümüze ulaşanların Osmanlı Dönemi'nde yapıldıkları bilinmektedir. Osmanlıların Anadolu'da inşa ettiği kapalı çarşıların bazıları ortadan kalkmışsa da, en önemlileri ya bütünüyle ya da bölüm hâlinde zamanımıza kadar gelmişlerdir. ${ }^{26}$

Bedesten kelimesinin aslı "Bezistan" veya "Bezzazistan" olup, bozularak "bedastan" veya "bedesten" haline gelmiştir. Bez ve bezze, kumaş ve harpte ganimet alınan eşya anlamına gelmektedir. ${ }^{27} \mathrm{Bu}$ modelde merkezde bedesten, bedesten etrafında gelişen sürekli açık çarşı ve bu yapıları tamamlayan belli günlerde açılan pazar yerleri bulunur. ${ }^{28}$ Bedestenler, Anadolu'da Selçuklu devrinin sonlarına doğru inşa edilmeye başlanmış, Anadolu Beylikleri döneminde gelişmiş, Osmanlı döneminde de hem sayı hem de karakteristik açıdan gelişmişlerdir.

Bedesten başlangıçta ahşap olarak yapılan mütevazı gözlerden ibaret dükkanların arasında, yani şehrin alışveriş merkezi ortasında kagir kütlesiyle yükselen belirgin bir yapı idi. Böylece bedesten Türk şehirciliğinde ticaret bölgesinin çekirdeğini teşkil ediyor, bütün alışveriş onun etrafında cereyan ediyordu. Bedestenin kagir ve sağlam yapılar olması, ahşap dükkanların yangınlarda yok olması göz önüne alınarak hiç değilse değerli mallan koruyabilmek bakımından daha emniyetli olmasıyla izah edilebilir. ${ }^{29}$ Bedestenlerde genelde değerli emtia satılması, mümkün olduğunca dışa kapalı inşa edilmelerine, pencerelerin küçük ölçülerde yapılmasına veya hiç pencere yapılmamasına neden olmuştur. Büyük servetler biriktirmiş paşalar, beyler, saray görevlileri gibi üst yönetici sınıf üyeleri ve zengin dini vakıflar, paralarını bedestenlerdeki tüccarlar vasıtasıyla işletirlerdi. Deniz aşırı ticaretin büyük bölümünü, mücevherat, pahalı dokumalar, kürk, baharat, ilaç, boya ve kokular gibi lüks tüketim maddeleri oluştururdu. Dolayısıyla, büyük tüccarlar, en çok bu malları alıp satar, çoğu işlerini

\footnotetext{
${ }^{24}$ Necdet Sakaoğlu, Geleneksel Meslek Örgütlenmeleri ve Anadolu Çarşıları, Osmanlı Çarşıları Atlası, Doğan Dergi Yayıncilik, Bursa 2010, s.17.

${ }_{25}$ Mohammad Gharipour, The Bazaar in The Islamic City / Design, Culture and History, The American University in Cairo Pres, Cairo and NewYork 2012, s.13

${ }^{26}$ Mustafa Cezar, Tipik Yapılarıla Osmanlı Şehirciliğinde Çarşı ve Klasik Dönem İmar Sistemi, Mimar Sinan Üniversitesi Yayını No:9, İstanbul 1985, s.126

${ }^{27}$ Gündüz Özdeş, Türk Çarşıları, Tepe Yayınları, Ankara 1998, s.7

${ }^{28}$ Kenan Mortan-Önder Küçükerman, Çarşı, Pazar, Ticaret ve Kapalıçarşı, Türkiye İş Bankası Kültür Yayınları, İstanbul 2007. s.111.

${ }^{29}$ Kenan İnan, "Bedestenlerin Türk Ticari Mimarisindeki Yeri ve Trabzon Bedesteni”, Osmanlı Tarihi Araştırma ve Uygulama Merkezi Dergisi OTAM, 2015, Say1 7, s.121-122
} 
bedestenden yönetirdi. ${ }^{30}$ Bir kente bedesten kurulabilmesi için ticaretin belirli vasıflara sahip olması gerekir. Bedesten kuruluşu padişah fermanı ve vezir hükmüne bağlanmıştır. ${ }^{31}$

Genel olarak işlevlerine göre hanlar; "menzil hanları" ve "şehir hanları" olarak ikiye ayrılabilirler. 15. yüzyıldan itibaren güçlenip merkezi otoritenin sağlandığ Devleti'nde, sayıca çoğalan bu yapılar, farklı kültür ve coğrafyadan gelen tüccarların tanışıp mal alışverişinde bulunduğu, getirdiği ürünü depolayabildiği, mümkünse konaklayabildiği mekânlar olarak kullanılmışlardır. Ticari amaçlı kullanılan şehir hanları, konaklama amaçlı han mimarisi ile plan şeması bakımından benzer inşa edilmişlerdir. Bu ticari hanlar, Osmanlılar döneminde yaygın olarak ortaya çıkan, yolcu konaklama işlevi taşımayan yapı türüdür. 15. ve 16. yüzyıllarda hanlar, genellikle 2 katlı olarak inşa edilmiştir. Anadolu'nun pek çok kentinde bulunan ticari hanlar, büyük ebatlı kütleleriyle dikkat çekmektedir. Genel olarak hanlar kâgir yâda yarı kagir olarak inşa edilmişlerdir. Ticari şehir hanlarını diğer tüm hanlardan ayıran en önemli unsur geceleri içinde kalınmamasıdır. Ticari şehir hanları dikkat çekici giriş kapıları ile avlu çevresinde sıralanmış odalar ve revaktan oluşmaktadır. Ticari hanlarda avluya bakan dükkân ve mahzenlerin yanı sıra, bedestenlerde olduğu gibi dışarıya açılan dükkânlar da yer alabilmektedir.

Hanlarda yer alan dişa bakan dükkânlar, iç kısımda yer alan mahzen ve dükkânlara göre daha büyüktür. Hanlarda; içe bakan dükkân ya da mahzenler, genel olarak 5-10 m2, dışa bakan dükkânlar ise $10-20 \mathrm{~m} 2$ arasında değişkenlik gösterip; içe bakan dükkânların daha küçük, dışarıya açılan dükkânların ise daha geniş olduğu görülür. ${ }^{32}$

Sonuç olarak Osmanl1-Türk kültüründe çarşı, kent için önemli bir mekânsal öğedir ve toplumun tüm kesimleri tarafından kullanılan kamusal alanlardır. Kentte toplumsal, idari ve ekonomik birçok faaliyet bu mekânda geçmektedir. 16. yüzy1lda belirginleşen geleneksel Türk çarşılarının klasikleşmiş mekânsal yapısı, 19. yüzyıldan itibaren değişime başlamış, 20. yüzyılın başlarında bu değişim devam etmiş ve esas olarak köklü değişimler 20 yüzyılın ikinci yarısında yaşanmıştır. 1980'lerden sonra ise liberal ekonomi çerçevesinde ticaret mekânlarına alışveriş merkezlerinin de dâhil olması ile geleneksel Türk çarşı geleneği tamamen farklı bir sürece girmiştir. ${ }^{33}$

\section{Osmanlı Çarşı Sisteminde Isparta Üzüm Pazarı Çarşısı}

Isparta bütünüyle ve kesin olarak 1204 yılında III. Kılıçarslan döneminde Anadolu Selçukluları, bünyesine, 1390 yılında ise Hamidoğlu beyliğinden Osmanlı devletine katılır. Osmanlı devletine katılmasının ardından 16. yy başlarına kadar, önemli bir siyasi olay gerçekleşmez. $^{34} \mathrm{Bu}$ durağanlık kent merkezinin fiziksel değişimiyle de paralellik gösterir.

\footnotetext{
${ }^{30}$ Halil İnalcık, Osmanlı Imparatorluğu Klasik Çă̆ (1300 1600), Çev. Ruşen Sezer, YKY, İstanbul 2009, s. 167168

31 Özcan Yurdalan, Çarşılarla Anadolu Bedestenler, Hanlar, Kapalıçarşılar, Halk Bankası Yayınları, İstanbul 2011, s.9-10

32 Özlem Atalan-Hasan Arel, “15. ve 16. Yüzyıllarda Yapılmıș Osmanlı Han Yapılarının Mekânsal Analizi”, Turkısh Studies, Vol.11/2, Ankara 2016, s. 217-228.

${ }_{33}$ Mehmet Uysal, "Tarihsel Süreçte Geleneksel Konya Çarşısı İçin Bir Mekansal Analiz”, Milli Folklor Dergisi, 2010, Say1 86, s.149-162

${ }^{34}$ Hulusi Turgut, Cumhuriyetten Günümüze Isparta, ABC Basın Ajans1, İstanbul 2000. s.40.
} 
Üzüm pazarı Isparta İli Merkez İlçe'de kentin en önemli düğüm noktasını oluşturan Kaymakkapı Meydanında bulunur. Bölge aynı zamanda Isparta kent merkezidir. Öyle ki kentin Ankara, İstanbul ve İzmir gibi büyük kentlere ulaşan Süleyman Demirel Bulvarı ve Mimar Sinan Caddesi; Konya bağlantısını oluşturan Atatürk Bulvarı; Antalya Bağlantısını oluşturan Adnan Menderes Bulvarı marifetiyle doğrudan Kaymakkapı meydanına ulaşır. Kaymakkapı meydanı ve çevresine yakından bakıldığında Hükümet Konağı, Eski Belediye Binası, Garnizon Komutanlığı, Ulu Cami, Firdevs Bey Cami ve Bedesteni, Dalboyunoğlu Hamamı ve Bey Hamamı gibi kentin önemli tarihi yapılar bölgede yer alır. 1936 yılında kente ulaşan demiryolu İstasyon Caddesi vasıtasıyla Kaymakkapı Meydanına eklemlenir. 1943'te Prof. Ölsner tarafından Isparta'da gerçekleştirilen ilk imar planı çalışmasında kent merkezi durumunu koruyan ve pekiştiren Kaymakkapı Meydanı, zaman içerisinde büyük düşümlere uğrayarak, günümüze değin önemini korumuştur. Bu dönüşümler sırasıyla 1930'lu yıllarda inşa edilen Hükümet Konağı, 1950'li yıllarda tamamlanan eski İş Bankası ve PTT binalarıyla başlar, 1960’lı yıllarda Büyük Isparta Oteli inşasıyla devam eder. ${ }^{35}$
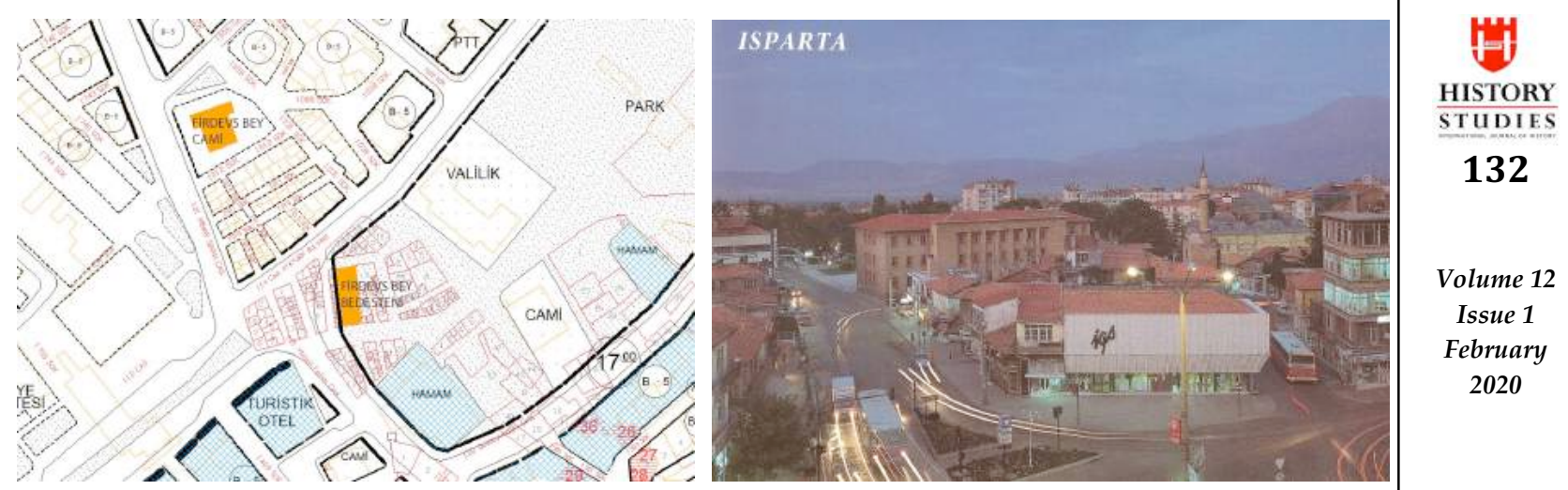

Şekil.1-2. 1990’lı yılların başında Firdevs Bey Bedesteni çevresinde yer alan arastalar ${ }^{36}$

1990'larda kavşağın batı tarafında yer alan ve "sıra mağazalar" olarak bilinen işyerleri ile arkasındaki mezarlık alanın kaldırılarak yerine 20 Ekim İş Han'ının yapılması ile Şekil 1ve 2'de görülen Bedesten çevresinde yer alan arastaların yıkılarak Şekil 3 ve 4'de görülen otopark ve çevre düzenlemesi yapılması bölgenin dönüşümde dönüm noktasıdır.

\footnotetext{
35 A.Şevki, Duymaz, "Kentsel Sit Bağlamında Geleneksel Bir Çarşı Örneğinin İrdelenmesi: Isparta Üzüm Pazarı”, Xvıı. Ortaçağ Türk Dönemi Kazıları ve Sanat Tarihi Araştırmaları Sempozyumu, 02-05 Ekim, İstanbul 2013.

${ }^{36}$ Isparta 2003 İmar Planından Düzenleme - Isparta Karpostalı, Keskin Color Matbaası
} 

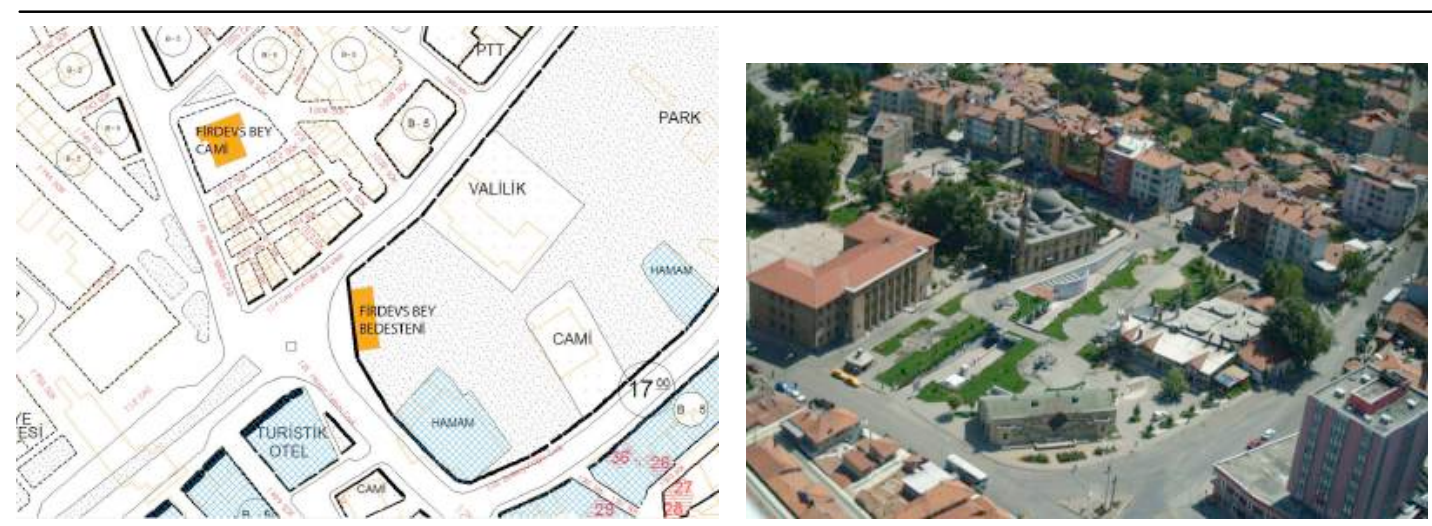

Şekil 3-4. 2000’li yılların başında Firdevs Bey Bedesteni çevresi ${ }^{37}$

Bölge tarihi belgelerde sınırları net olarak belirlenemeyen Şeyh Mahallesi ve Camii Atik Mahallesinde yer aldığı bilinmektedir. Bir süre Mimar Sinan Camisi (Firdevs Bey Cami) nedeniyle Sinan mahallesi olarak adlandırılan mahallenin adı günümüzde Kutlubey mahallesidir. Okulları camileri, çarşısı, pazarları, hanları ile şehrin ekonomik ve fiziksel merkezi konumundadır. Çoğunlukla ahşap dükkalardan oluşan çarşı, yangınlardan ve depremlerden büyük zarar görmüştür. ${ }^{38}$ Ayrıca tarihi kaynaklardan bölgede Kerimpaşa,

HISTORY STUDIES

133

Volume 12

Issue 1

February

2020

Antalyalığlu, Hatipoğlu, Alaybeyoğlu, Pamuk, Vakıf, Kereste ve Nalbant hanlarının olduğu anlaşılmaktadır. Ancak bu hanların hiç biri günümüze ulaşmamıştır. ${ }^{39}$

Tarihsel süreç içerisinde sokakların iki yanında yer alan küçük ölçekli dükkânların arasta şeklinde teşekkül etmesinden meydana gelen çarşıda yer alan ahşap dükkânların büyük çoğunluğu 1950'li yıllardan itibaren betonarme karkas yapılara dönüşmüştür. Ancak alanın genel Osmanl1-Türk Çarşısı formuna uygun yapısı ve içerisinde barındırdığı tarihi taş yapılı dükkânlar nedeniyle Antalya Kültür ve Tabiat Varlıklarını Koruma Kurulunun 28.07.1992 tarih ve 1495 sayılı kararı gereğince alan kentsel sit alanı ilan edilmiştir.
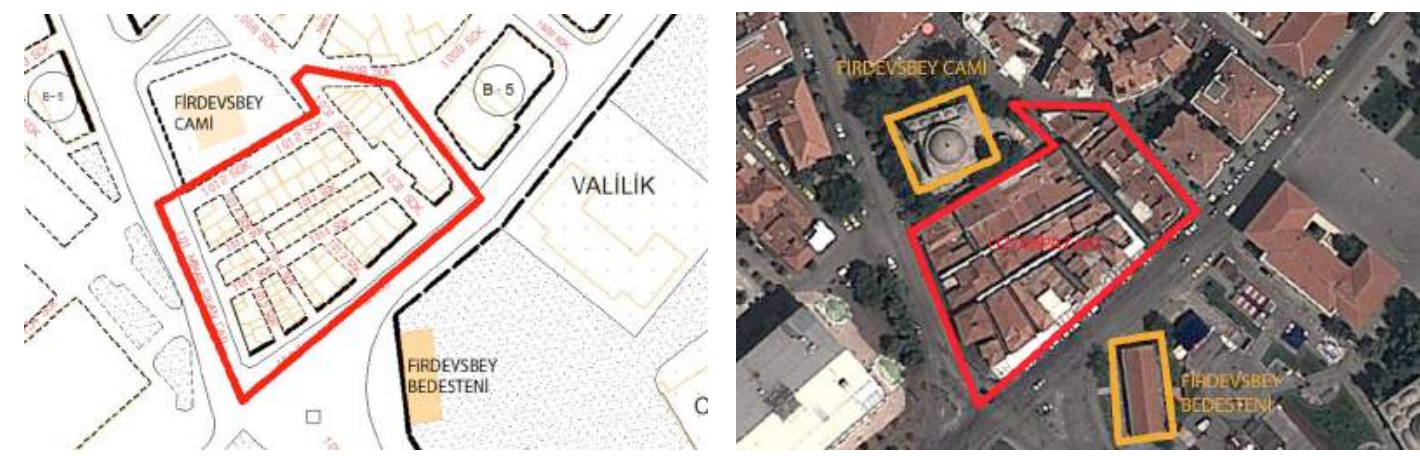

Şekil 5-6. Üzüm Pazarı Kentsel Sit Alanı ${ }^{40}$

37 Isparta 2003 İmar Planından Düzenleme-http://fotokent.blogspot.com/2011/05/isparta-resimleri.html (E.T.15.09.18)

${ }^{38}$ A. Nuri Erçetin, Bir Zamanlar Isparta, Erçetin AŞ Yayını, İzmir 2014, s.56.

${ }^{39}$ A Şevki Duymaz, "Isparta ve Çevresinde Yer Alan Türk Dönemi Mimari Eserler”, Geçmişten Günümüze Isparta,

Haz: Hüseyin Gül-Songül Boybeyi, Atatürk Kültür Merkezi Yayını:360, Ankara, 2009, s. 218

${ }^{40}$ Isparta 2003 İmar Planından Düzenleme-Google Earth Görüntüsü Düzenleme

\section{History Studies}


Çarşıda yer alan 109 dükkândan 16 tane tarihi dükkân tescillenmiştir. Şekil 5 ve 6'da Kentsel Sit Alanının sınırları gösterilmiştir. Üzüm pazarı isminin geçmişte bu bölgede kurulan pazarda tacirlerin başka yörelerden getirdikleri üzümleri satmasından kaynaklandığı, pazarın üst tarafında yer alan çeşmenin isminin ise benzer şekilde çevresinde kurulan karpuz pazarında olayı karpuz çeşmesi olduğu düşünülmektedir. ${ }^{41}$ Ancak pazarın isminin pek çok Anadolu kentindeki geleneksel Osmanlı dönemi üstü açık çarşılarında görüldügü̈ üzere yazın güneşten korunmak için sokakların üzerine sardırılan asmalardan dolayı üzüm pazarı olması da muhtemeldir.

Çalışmada Üzüm Pazarındaki yapısal inceleme Firdevs Bey Cami ve Bedesteni, Tarihi taş dükkanlar ve 1950 sonra inşa edilen betonarme dükkanlar olmak üzere üç bölümde yapılmıştır.

\subsection{Firdevsbey Cami ve Bedesteni}

Üzüm pazarı ile ilgili gelişim süreci incelenirken Firdevs Bey Cami ve Bedestenin yapılışını sürecin başlangıcı olarak kabul etmek gerekecektir. Firdevs Bey Cami Kanuni Sultan Süleyman döneminde, hicri 977, miladi 1561yılında, Isparta Mütesellimi (Valisi) bulunan Firdevs Paşa tarafından yaptırılmıştır. ${ }^{42}$ Üzeri kurşun kaplı tek kubbeli cami, yöresel köfke taşından kâgir olarak inşa edilmiştir. Batı cihetinde bir minaresi bulunmaktadır. Mimar Sinan'ın yaptırdığ 1 binaların adlarını ve yerlerini gösteren Tezkiratül-Enbiya adlı listede bu caminin 78. yapı olarak yer aldığından bahsedilmektedir. ${ }^{43}$

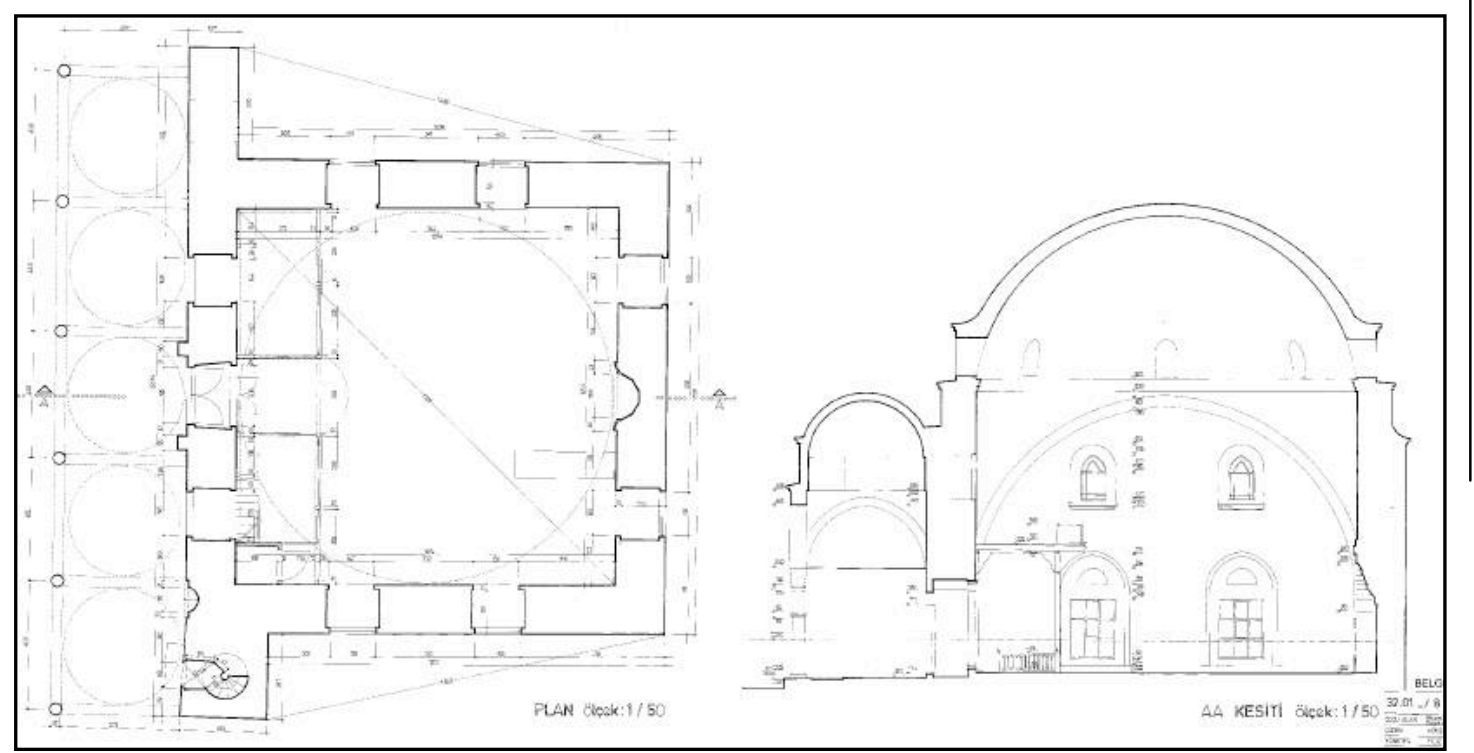

Şekil 7. Firdevs Bey (Mimar Sinan) Cami ${ }^{44}$

Bir başka iddia ise yaptıranına izafeten Osmanlı arşiv vesikalarında "Firdevs Paşa" diye isimlendirilen Şekil 7'de plan ve kesitine yer verilen caminin Mimar Sinan Camii olarak anılması projesinin Mimar Sinan eserlerinden tip proje olarak yapılmasından dolayıdır. Evliya

${ }^{41}$ Selçuk Demirgil, Mazideki Isparta -1, Isparta Belediyesi Yayınları, Isparta 2007.

${ }^{42}$ Aptullah, Kuran, Mimar Sinan, Hürriyet Vakfı Yayınları, İstanbul 1986, s. 277

${ }^{43}$ Böcüzade Süleyman Sami, Isparta Tarihi, Serenler Yayınevi, İstanbul 1983.

${ }^{44}$ Vakıflar Genel Müdürlüğü Arşivi, Ankara 1980.

\section{History Studies}

Volume 12

Issue 1

February

2020 
Çelebi'nin, Seyahatnamesi'nde Isparta'dan bahsederken “evvela Firdevs Bey Camiini Koca Sinan bina etti” ifadesi bulunmaktadır. ${ }^{45} \mathrm{Bu}$ nedenle cami günümüzde Mimar Sinan Cami olarak bilinmektedir.

Firdevs Bey Cami hakkında ulaşılabilen eski tarihli görsel belge sayılabilecek Şekil 8'de gösterilen 1925 tarihli fotoğrafta caminin minaresin olmamas1 1914 depreminden zarar görmüş olabileceği fikrini ortaya koymaktadır. Cami çevresinde ise 1-1.5 katlı yer yer beşik ve kırma çatılı taş dükkanlar dikkat çekmektedir.

HISTORY

STUDIES

135

Volume 12

Issue 1

February

2020

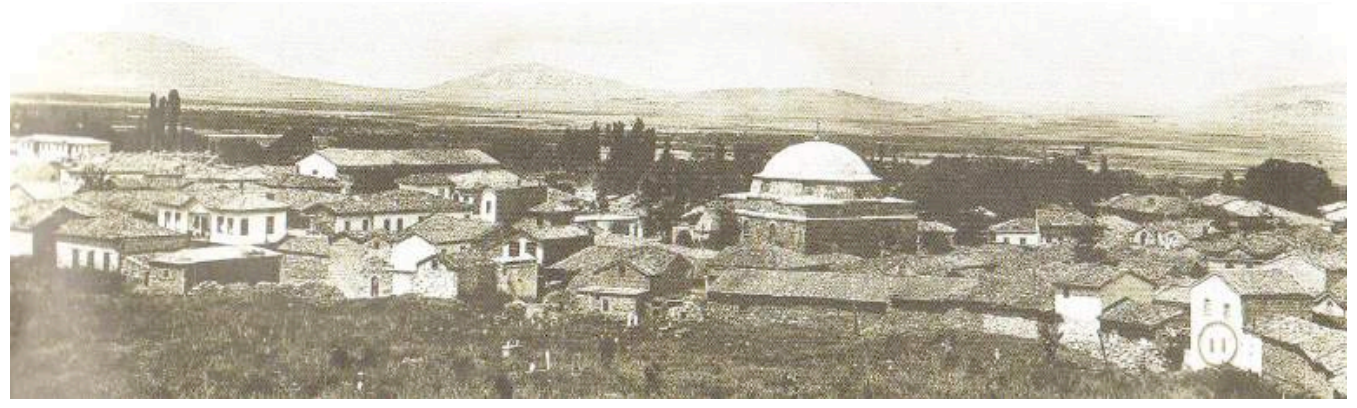

Şekil 7. Firdevs Bey Cami ve Çevresi $1925^{46}$

Firdevs Bey cami yapılırken yanına bir zaviye bir de bedesten yaptırmıştır. Günümüzde bu zaviye bulunmamakta, ancak bedesten hâlâ mülkiyeti Vakıflar Genel Müdürlüğü'ne bağlı olmak üzere ayakta durmaktadır. Şekil 8'de plan ve kesitine yer verilen Bedesten Mimar Sinan Camii vakıflarına gelir olması amacıyla inşa edilmiş, vakıf dükkânlar tesis edilmiştir. Firdevs Bey yaptırmış olduğu camiye gelir olması için bedesten ve etrafını çevreleyen arsayı vakfetmiştir. $^{47}$

\footnotetext{
${ }^{45}$ Sadık Akdemir, XVIII. Yüzyılın Illk Yarısında Isparta, Isparta Valiliği İl Kültür ve Turizm Müdürlügü Yayınları, Isparta 2008, s.187.

${ }^{46}$ Isparta Valiliği, Isparta 1880-1980, İl Özel İdare Müdürlüğü Yayını, Isparta 2001,s.25

${ }^{47}$ Sadık Akdemir, XVIII. Yüzyılın İlk Yarısında Isparta, Isparta Valiliği İl Kültür ve Turizm Müdürlüğ̈̈ Yayınları, Isparta 2008, s.188.
}

\section{History Studies}




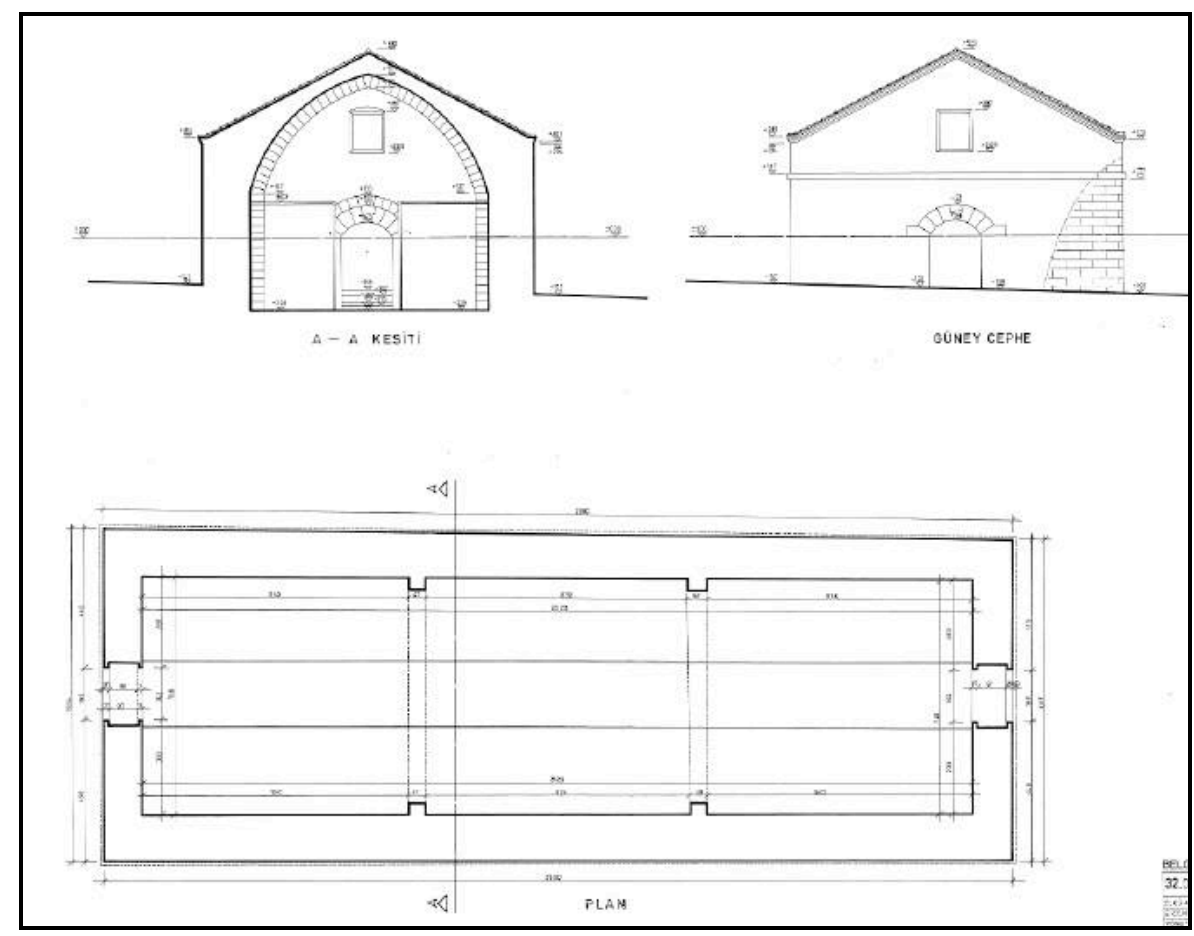

Şekil 8. Firdevs Bey Bedesteni ${ }^{48}$

HISTORY

Firdevs Bey Bedesteninin yan duvarları moloz taş duvar giriş kapılarını barındıran cepheleri kesme kövke taş duvardan inşa edilmiş yapı içerisinde 12 adet ahşap dükkân barındırır. Yapının beşik çatısı kurşun kaplı olarak inşa edilmiş ancak kurşun kaplamanın zaman içerisinde sökülerek cami kubbesinin onarımında kullanılmış, bedestenin çatısına kiremit kaplanmıştır. ${ }^{49}$ Yapıldığı dönemde ipekli kumaş ticareti yapılan bedesten, bir dönem sarraflar çarşısı olmuş, bir dönemde depo olarak kullanılmıştır. Bedestenin korunaklı yapısı, 1816 ve 1851 tarihlerinde yaşanan büyük çarşı yangınlarından ve 1914 depreminden fazla etkilenmemesine olanak sağlamıştır.

\subsection{Tarihi taş dükkanlar}

2019 itibariyle üzüm pazarı kentsel sit alanı 8 imar adasında 16 tanesi tescilli 114 adet irili ufaklı dükkândan oluşmaktadır. Alandaki 16 adet Şekil 9'da gösterilen tescilli dükkânlar şunlardır. 383 ada 3 parsel, 387 ada 9-10 parsel, 389 ada 10-12-13 parsel, 391 ada 1-2-7-9 parsel, 398 ada 2-4-5-6-8-9 parsel.

${ }^{48}$ Vakıflar Genel Müdürlüğü Arşivi, Ankara 1980.

${ }^{49}$ Böcüzade Süleyman Sami, Isparta Tarihi, Serenler Yayınevi, İstanbul 1983.

\section{History Studies}

Volume 12 


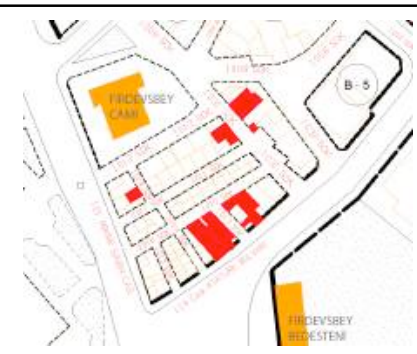

Şekil 9. Üzüm Pazarında yer alan tarihi taş dükkanlar ${ }^{50}$

Üzüm pazarında yer alan 16 adet tarihi taş dükkânın sözlü anlatımlarda Isparta'daki zengin gayrimüslim tüccarlara ait olduğu bu tüccarların mübadele döneminde işyerlerini satarak şehirden ayrıldıkları iddia edilmektedir, ancak arşiv taramasında net bir bilgiye ulaşılamamıştır. $\mathrm{Bu}$ dükkanların 3 tanesi dışında diğerleri iki katlıdır. Bodrum katlarda ve zemin katlarda yöresel andezit, üst katlarda bir tür volkanik kayaç olan yörede kövke olarak adlandırılan hafif ve kolay işlenir taş malzeme kullanılmıştır. 1. kat döşemeleri tuğlalı volta döşemedir. Bazı dükkanlarda çatı konstrüksiyonu da bu yöntemle ancak tuğla yerine kövke taşı kullanılarak inşa edilmiştir. Üst katlarda demir kepenkli, kemerli pencereler bulunur. Binalar bodrum üzeri 2 kattan oluşsa da yeterli alan olmadığı için dükkanlar bünyesinde merdiven bulundurmaz. Geçmişte katlar arası ulaşım kapaklarla, dış pencerelere yerleştirilen seyyar merdivenlerle veya iki dükkan arasına inşa edilen $50 \mathrm{~cm}$ genişliğindeki taş merdivenlerden sağlanmıştır. Genel olarak dükkanların zemin katı satış, bodrum ve 1. katı depo amaçlı inşa edilmiştir. Tek hacimden oluşan, arsasını tam kullanan dükkanlarda plan tipolojisinden bahsetmek mümkün değildir. Cephe tipoloji olarak ise tescilli dükkanları tek kat ve çift kat olmak üzere düz çatılı ve

Volume 12 Issue 1 February 2020 beşik çatılı biçiminde sınıflandırmak mümkündür. Aşağıda Şekil 10'da bu sınıflandırma bir arada verilmiştir.

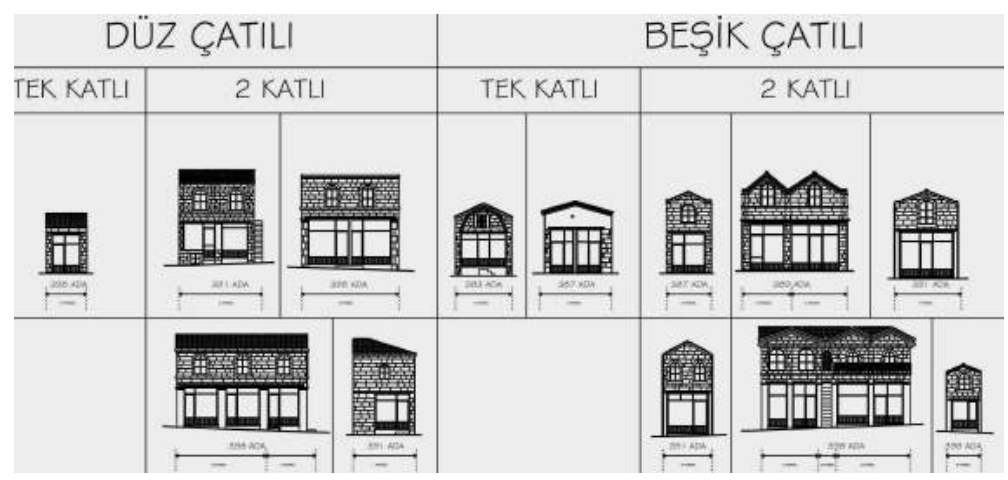

Şekil 10. Tarihi taş dükkanların cephe tipolojisi ${ }^{51}$

\subsection{Betonarme dükkanlar}

Üzüm pazarı oluşturan Yap1 grubunda üçüncü bölümü oluşturan arasta düzenindeki ahşap dükkanların ise yaşanan yangın ve deprem felaketlerden büyük zarar gördüğü bilinmektedir.

\footnotetext{
${ }^{50}$ Isparta 2003 İmar Planından Düzenleme

${ }^{51}$ Cevat Çevrimli-Hasan Haştemoğlu, "Kültürel Sürdürülebilirlik Açısından Isparta Üzüm Pazarı", International Congress of the New Approaches and Technologies for Sustainable Development, September 21-24, Isparta 2017.
} 
1950'li yıllardaki imar planı ve kadastro çalışmalarının ardından ahşap dükkanların yerini günümüze değin ulaşan 1-3 katlı betonarme dükkanlar almış, bu yapılar ayakta kalan az sayıdaki tarihi taş dükkanların çevresini sarmıştır. Sözlü kaynaklarda anlatıldığı üzere Üzüm Pazarı çok farklı işyerlerini bünyesinde barındırmakta, yer yer işyerlerinin gruplanmasıyla sokaklar Kebapçılar arastası, Kunduracılar arastası gibi isimler almaktadır. Adı geçen meslek gruplarının büyük çoğunluğu gruplanmalar bulunmasa da alanda yer almaya devam etmektedir. İrili ufaklı bu dükkanlar 1959 yılında tapu kayıtlarına geçmiş, büyük çoğunluğu kargir dükkan/mağaza olarak adlandırılmıştır. Tapu kayıtlarında çok az sayıda otel, fırın, ahşap dükkan, arsa, ev olarak kayıtlı iş yeri vardır. Bir işyeri dışında kat mülkiyeti oluşmamıştır. İş yerlerinin çok büyük bölümü özel şahıslara aittir. Bu dükkânların büyük çoğunluğu teras çatılı yapılmıştır. Şekil 12'de 1950 yılında çekilmiş hava fotoğrafında alanın tamamen yapılaştığ 1 eski taş dükkânların ise kiremit çatıları ile hemen fark edildiği görülmektedir.

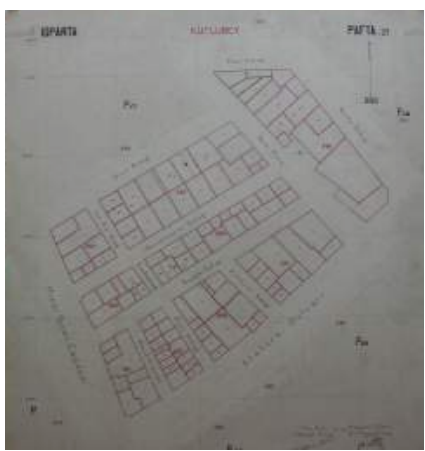

Şekil 11. 1959 Kadastro Paftasi ${ }^{52}$

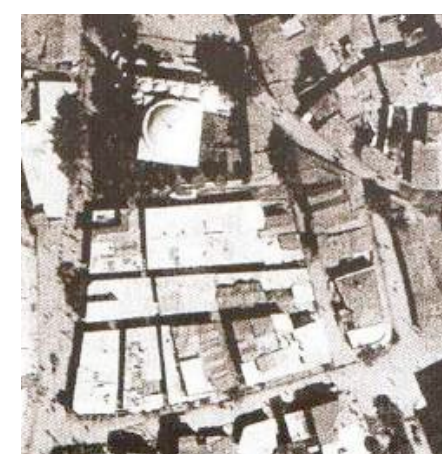

Şekil 12. 1950 Hava fotoğrafi ${ }^{53}$

Ancak arasta kavramı ve çarşı kültürü yaşamaya devam etmiştir. Alanın ile ilgili Isparta'nın en eski fotoğraf stüdyosu niteliğindeki Foto Rekor arşivinden edinilen Şekil 13 ve 14'de yer verilen fotoğraflarda 1950 sonrası döneminde inşa edilen dükkanların önce tek katlı betonarme kargir olarak inşa edilip daha sonra zam içerisinde birinci katların ve ahşap konstrüksiyonlu kiremit örtülü çatıların yapılara eklendiğini göstermektedir.
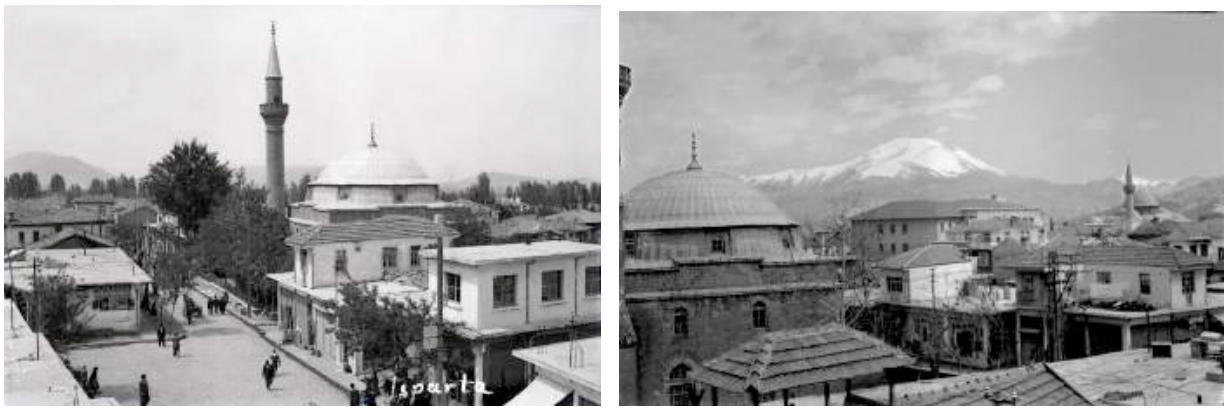

Şekil 13-14. Firdevs Bey Cami ve Üzüm Pazarı çevresi ${ }^{54}$

\footnotetext{
${ }^{52}$ Isparta Tapu ve Kadastro Müdürlüğü Arşivi, Isparta 1959.

53 Isparta Valiliği, Isparta 1880-1980, İl Özel İdare Müdürlüğü Yayını, Isparta 2001,s.62

${ }^{54}$ Isparta Foto Rekor Arşivi, Isparta
} 
Ayrıca 1996 yılında dönemin Isparta Belediye'si tarafından sokakların üzeri şeffaf polikarbon malzeme ile kapatılarak, kapalı çarşı oluşturulmaya çalışılmıştır. Aşağıda Şekil 15 'de yer alan kartpostal resminde Şekil 16'da 1998 yılında çekilmiş fotoğrafta bu durum belirtilmiştir. Herhangi bir altyapı çalışmasının bulunmadığı arastalarda mevcut dükkân sahipleri tarafindan desteklenen uygulama 2008 yılında dönemin Isparta Belediyesince yenilenmiştir. Ancak özellikle tescilli dükkânların cephe algısına büyük zarar veren uygulamanın Antalya Bölge Kurulu tarafından kaldırılması karara bağlanmıştır.

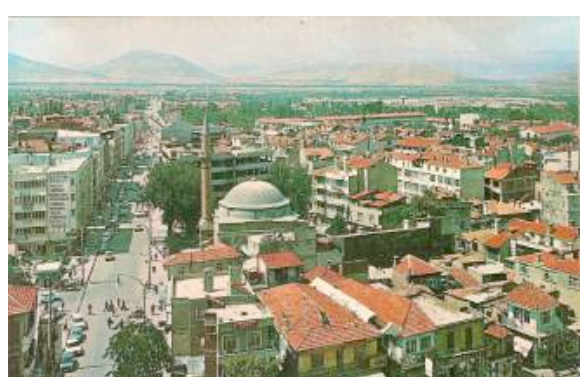

Şekil 15. 1996 öncesi durum ${ }^{55}$

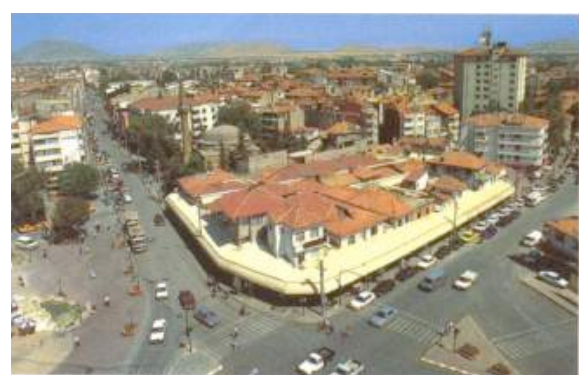

Şekil 16. 1996 sonrası durum ${ }^{56}$
HISTORY

STUDIES

139

Volume 12

Issue 1

February

2020

Sonuç olarak süreç içerisinde yaşanan dönüşümler sonucu Üzüm Pazarı kentsel sit alanı ve çevresi bugün ki çarpık yapılaşamaya maruz kalmış kent merkezinde önemli bir sorun haline dönüşmüştür. Antalya Kültür ve Tabiat Varlıklarını Koruma Kurulunun 28.07.1992 tarih ve 1495 sayılı kararı gereğince alan kentsel sit alanı ilan edilen alana geçen 15 yılı aşkın süreçte gerekli yapısal düzenlemeler hayata geçirilememiştir.

\section{Araştırma Bulguları; Üzüm Pazarı Kentsel Sit Alanında Mevcut Sorunlar}

Altyap 1 Sorunları:

Elektrik hatlarının üst örtü yapılması esnasında plastik borular içerisinden geçirilerek üst örtüye bağlanmıştır. Bu nedenle üst örtü sökülmesi sonucu tüm tesisatlar açıkta kalacaktır. Bina cephelerine monte edilmesi görüntü açısından uygun olmadığından ve elektrik direği dikmek için yeterli alan bulunmadığından dolayı, üst örtünün sökülmesi sonrasın da elektrik hatlarının ivedi biçimde yer altına alınması gerekmektedir. Üst örtü ile bağlantılı bir diğer alt yapı sorunu yağmur suyu problemidir. Mevcut durumda üst örtüde toplanan yağmur suları belirli noktalardan Ø12 plastik borular ile yer altına aktarılmaktadır. Üst örtünün kaldırılması ardından her parselin çatısından birbirinden bağımsız yağmur iniş boruları indirilmesi gerekecektir.

İklimlendirme Sorunlar1:

Alanda iklimlendirme ile ilgili sorunların ilki 1sıtma-soğutma sorunları olarak adlandırılabilir. Alan yer alan işyerlerinin büyük kısmı 1sıtma-soğutma problemini klima ile çözümleme yoluna gitmektedir. Isıtma için işyerlerinin bir kısmında elektrikli infrared isıtıcı, katalitik soba vb. kullanılmakta, çok az sayıda işyerinde geleneksel odun-kömür sobası yakılmaktadır. Bu nedenle özellikle cepheye yerleştirilen klima motor üniteleri görsel kirliliğe neden olmaktadır. Alanda iklimlendirme ile ilgili sorunların bir diğeri güneş ve yağmur kontrolüdür. Çarşıdaki işyerlerinin küçük boyutlarda olması esnafı mallarını dışarıda teşhir etmeye yöneltmekte bu durum güneş ve yağmur kontrolünü daha zorunlu hale getirmektedir.

\footnotetext{
${ }^{55}$ Kartpostal-Ticaret Matbaası, Isparta

${ }^{56}$ Sidıka Çetin, "Dönüşüm sürecinin tarihi kent merkezleri üzerine etkileri: Isparta örneğinde bir inceleme", Erciyes Üniversitesi Fen Bilimleri Enstitüsü Dergisi, 27(2): 185-199 Kayseri 2011,s.195
} 
Parsel Büyüklüğü Sorunları:

Alanda kadastro ve tapu kayitlarına göre 109 adet parsel vardır. 2 adet Belediye mülkiyetinde parsel boştur. 3 adet parsel üst katlara ulaşım için ortak mülkiyetli merdivene ayrılmıştır. Kalan 104 parselin 38 âdetinin dar kenarı 3m'den küçük, 57 âdetinin dar kenarı $3 \mathrm{~m}$ 'den büyük 6m'den küçük ve sadece 9 âdetinin dar kenarı $6 \mathrm{~m}$ 'den büyüktür. Bu durum toplam alanın \%52'sinde parsel dar kenarının 3m'den küçük olduğunu göstermektedir. Toplam parsellerin $\% 87$ ise dar kenarı 6m'den küçük parsellerdir.

\begin{tabular}{lllll}
\hline $3 \mathrm{~m}>\mathrm{P}$ & $3 \mathrm{~m}-\mathrm{P}-6 \mathrm{~m}$ & $\mathrm{P}>6 \mathrm{~m}$ & Merdiven & Boş \\
\hline 38 Parsel & 57 Parsel & 9 Parsel & 3 Parsel & 2 Parsel \\
\hline
\end{tabular}

Tablo 1. Dar Kenar Uzunluğuna Göre Parseller

Alanda bulunan parseller alan olarak incelendiğinde ise toplam parsellerin \%60'nın $20 \mathrm{~m}^{2}$ 'den küçük olduğu görülür. \%26's1 ise $10 \mathrm{~m}^{2}$ 'den daha küçüktür.

\begin{tabular}{lllllll}
\hline $0-10 \mathrm{~m}^{2}$ & $10-20 \mathrm{~m}^{2}$ & $20-30 \mathrm{~m}^{2}$ & $30-40 \mathrm{~m}^{2}$ & $40-50 \mathrm{~m}^{2}$ & $50-60 \mathrm{~m}^{2}$ & $\mathrm{P}>60 \mathrm{~m}^{2}$ \\
\hline 28 & 37 & 16 & 13 & 2 & 6 & 7 \\
\hline
\end{tabular}

Tablo 2. Alan Büyüklüğüne Göre Parseller

Alanda görülen parsel büyüklügü sorunlarından bir diğeri alan küçüklüğünden kaynaklanan mimari yetersizliklerdir. 109 parsel üzerinde bulunan 114 adet işyeri incelendiğinde bu sorun üç ana grupta toplanabilir.

Birincisi alanda bulunan işyerlerinin büyük bölümü bodrum, zemin ve birinci kat olmak üzere üç katlıdır. Ancak alan yetersizliğinden işyerlerinin büyük bölümüne mimari standartlara uygun merdiven çözmek mümkün değildir. Pek çok işyerinde katlar arasında bulunan kapaklara seyyar merdivenler veya gemici merdiveni olarak tanımlanabilecek basit merdivenlerle ulaşım sağlanmaktadır. İkinci sorun tuvalet-lavabo mekânlarının büyük ölçüde standart dışı olması, pek çoğu sonradan eklendiği için havalandırma koşullarını sağlamamasıdır. İşyerlerinin büyük kısmında ise mekân yetersizliğinden tuvalet bulunmamaktadır. Üçüncü sorun ise küçük işyerlerine sığamayan işyerlerinin büyük ölçüde sokaklara taşması sonucu sokakları daraltmasidir.

Güvenlik Sorunları:

Alanda az sayıda kuyumcu, sarraf, saatçi ve gümüş̧̧ü işyeri bulunmaktadır. Bu işyerlerinin büyük çoğunluğu ise 101. Mimar Sinan ve 114. Atatürk Caddelerine cephelidir. Bu işyerleri dışında bazı işyerlerinin başta kepenk ve güvenlik kamerası olmak üzere güvenlik önlemleri vardır. Ayrıcı esnaf tarafından çarşı geneline güvenlik kameraları takılmıştır. Ancak mevcut işyeri kullanıcılarına sorulduğunda işyeri sahiplerinin büyük çoğunluğu güvenlik önlemlerini yetersiz bulduğunu bildirmiştir. İşyeri sahiplerinin diğer dikkat çektiği husus ise çarşı içerisinde aydınlatmanın yetersiz olduğudur. Diğer taraftan özellikle vatandaşların akşam saatlerinde işyerlerinin kapanmasının ardından çarşı içerisindeki sokakları kullanmaktan kaçındığ bilinmektedir. 
Görsel alg1 ve estetik sorunları:

Alanda geçmişten günümüze bina yüksekliği farklılıkları ve üst kat kullanım sorunları yaşanmaktadır. Çarşıda mevcut tescilli işyerleri de dâhil olmak üzere işyerlerinin tamamına yakını kat adedi aynıda olsa farklı yüksekliklere sahiptir. Öyle ki her işyeri plansız biçimde farklı tarihlerde sahibinin ihtiyaçları ve ekonomik gücü ölçüsünde inşa edilmiştir. pek çoğu zemin kat olarak inşa edilmiş zaman içerisinde ihtiyaç duyuldukça birinci hatta yer yer ikinci katlar ilave olmuştur. Ancak üst katlar inşa edilse de geçmişten günümüzü bu katları verimli kullanmak mümkün olmamış, üst katların kullanım amacı depo fonksiyonunun ötesine geçememiştir. Az sayıda kullanılan üst katın aksine büyük bir bölümü de uzun yıllar metruk biçimde kalmıştır. Günümüzde çok az sayıdaki büyük ölçekli işyeri dışında üst katlar depo olarak kullanılmaya devam etmekte veya atıl biçimde kullanım dışı bulunmaktadır. Alanda görülen görsel alg1 ve estetik sorunlarından bir diğeri farkı tabela biçimleri ve vitrinlerde görülen uyumsuzluktur.

Alanda yer alan işyerlerinin küçüklüğü işyeri sahiplerini vitrinlerini sokak yönünde çıkma yaparak yer kazanmaya yönlendirmektedir. Bu durum hem sokağ daraltmakta hem de görsel algıyı bozmaktadır. Alanda görülen görsel algı ve estetik sorunlarından en önemlisi ise binalarda oluşan mimari eleman ve malzeme uyumsuzluğu olarak adlandırılabilir. Zaman içerisinde çarşıda bulunan işyerlerinin cepheleri ahşaptan, plastiğe, tuğladan alüminyum kompozite kadar pek çok farklı malzeme ile kaplanmıştır. Arasta olgusuna zarar veren arka

HISTORY STUDIES

141

Volume 12 Issue 1 February 2020 sokağa bakan vitrinleri duvar örerek kapatma, pencere boyutlarını farklılaştırma, dıştan baca ekleme gibi uygulamalarsa sorunları büyütmektedir.

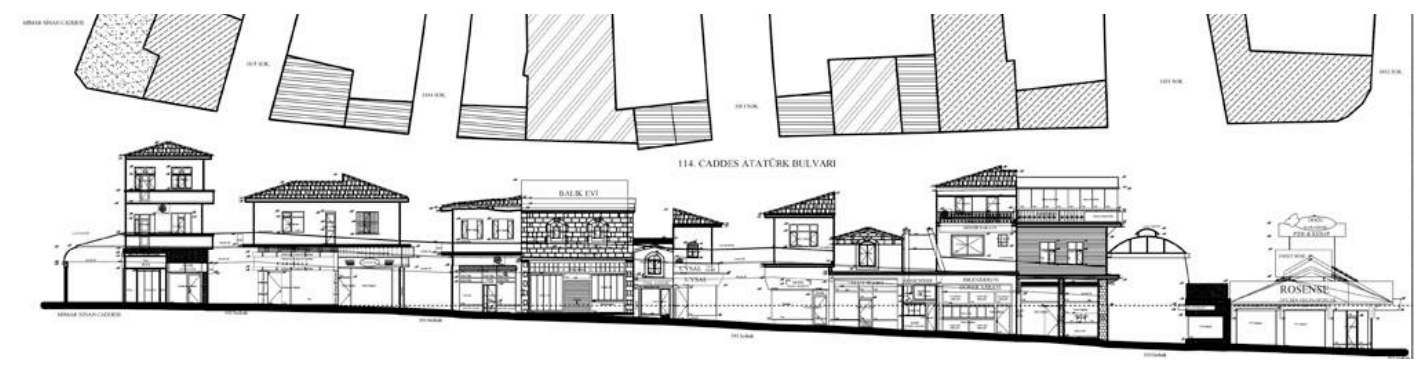

Şekil 17. 114. Cadde Atatürk Bulvarı rölöve cephesi ${ }^{57}$

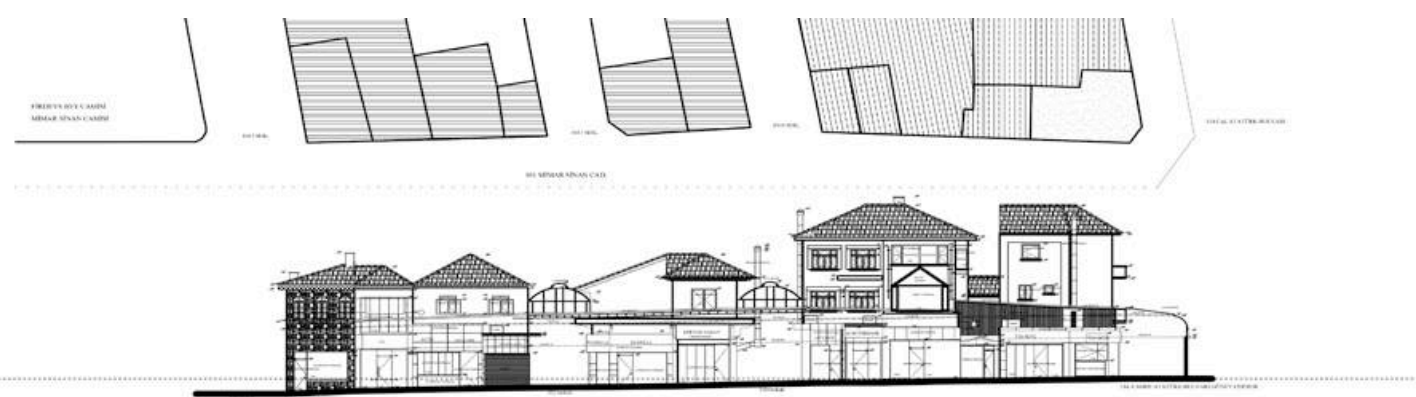

Şekil 18. Mimar Sinan Caddesi rölöve cephesi

\footnotetext{
${ }^{57}$ Çizimler: H.Haştemoğlu
} 


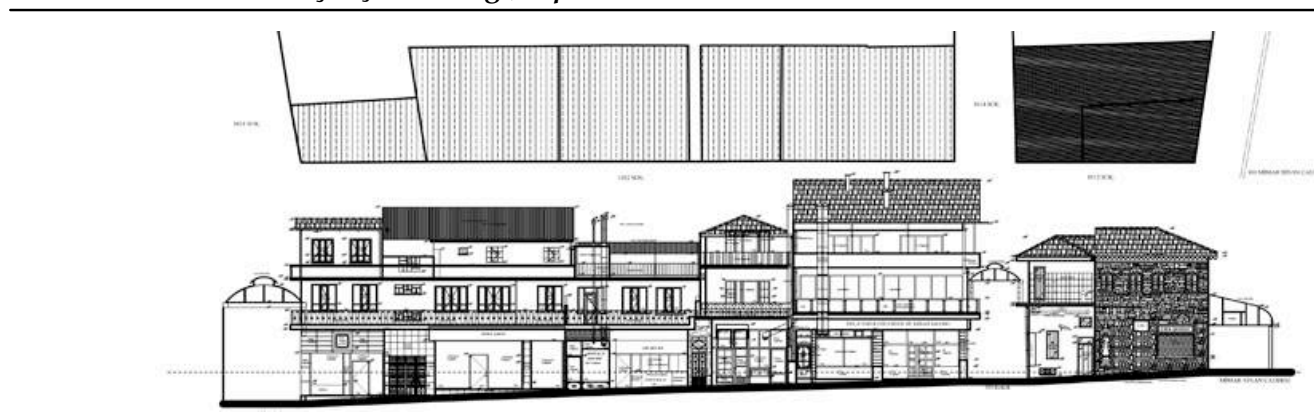

Şekil 19. 1012 Sokak rölöve cephesi
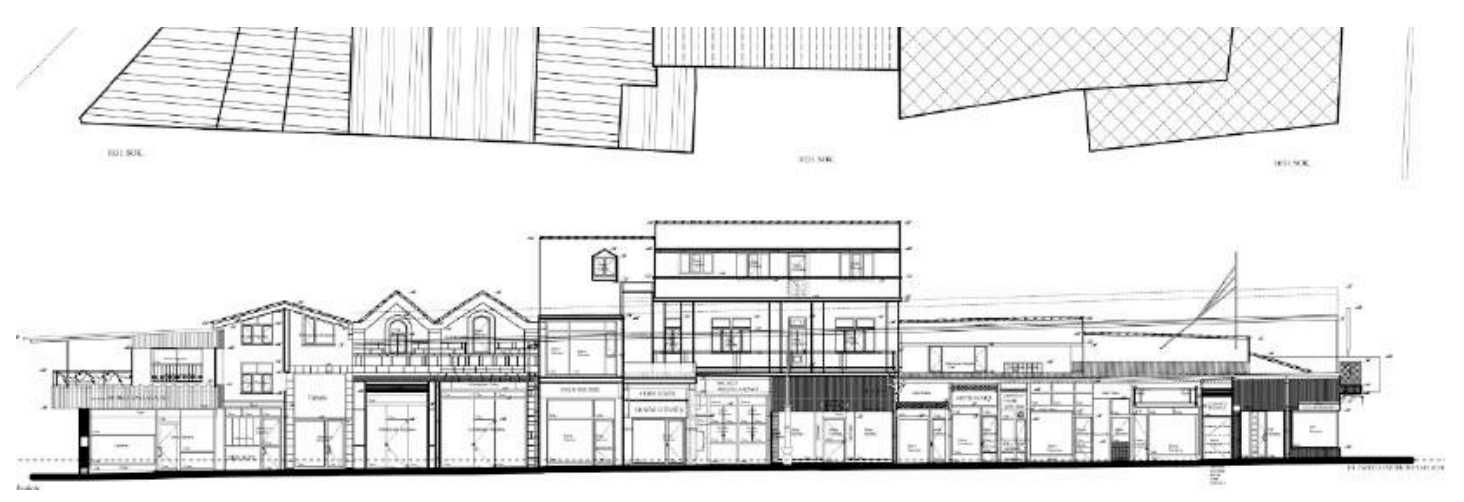

Şekil 20. 1031 Sokak rölöve cephesi

\section{Sonuç}

Isparta Üzüm Pazarı yakından incelendiğinde, klasik Osmanlı dönemi Türk Çarşılarının pek çok fiziki özelliğini yansıtmakla birlikte, Anadolu'nun diğer geleneksel çarşılarıyla benzer dönüşümler sergilediği görülür. Öyle ki;

Kent merkezinde yer alır.

16. yüzyılda şekillenmeye başlamıştır.

Bir Cuma Camisi (Firdevsbey Cami) çevresinde gelişmiştir.

Bünyesinde bir bedesten barındırır.

Sokaklar üzerine sırt sırta yerleştirilmiş küçük ebatlı dükkânlardan oluşur.

Zaman içerisinde sokaklarda arasta kavramı yerleşmiştir.

19.yüzyılda değişim geçirmeye başlamıştır.

20. yüzyılın ikinci yarısında ve 1980’ler sonrasında büyük değişimlere uğramıştır.

Bu noktalardan hareketle Üzüm Pazarı için Klasik Osmanlı Türk Çarşıları arasında, Üstü Açık Çarşılar sınıfında yer alan bir çarşıdır demek mümkündür.

Ancak oluşan yoğun trafik sirkülâsyonunun, tescilli yapıların ve kentsel sit alanlarının bölgedeki fazlalılığı nedeniyle çözümlenememesi, zaman zaman yerel yönetimleri alt geçitli 
kavşak projeleri, Mimar Sinan Caddesinin trafiğe kapatılması ve benzeri projelere yöneltmektedir. Gelecekte de yaşayan bir organizma olan kent formu değiştikçe kentin merkezi durumundaki Kaymakkapı Meydanının da dönüşümü kaçınılmazdır. Tescilli yapı olmayan dükkanlar alanda yeni projelerin hayata geçirilmesinde avantaj olabilecek niteliktedir. $\mathrm{Bu}$ grupta yer alan 100'e yakın dükkanın tarihi dokuya uygun biçimde yenilenmesi ivedi arz etmektedir. Özellikle gül ve el halısıyla ünlü Isparta kentinin merkezinde yer alan çarşının bütüncül projelerle ele alınması, günümüz yarı açık alış veriş merkezi mantığında turistik amaçlı olarak yeniden düzenlenmesi uygun olabilir. Öyle ki sokak girişlerine kapı düzenlemesi yapılması, tescilli, dükkanların bulunduğu arastalar dışında yer yer sokakların üzerinin örtülmesi mümkündür. Sonuçta her ne kadar değer kaybetmiş olsa da Geleneksel Osmanlı çarş1 anlayışını yansıtan alan korunmayı hak etmekte, yüksek turizm potansiyeli kente sorun olmak yerine, katkı sağlaması mümkün görünmektedir.

\section{Kaynaklar}

AHUNBAY, Zeynep - Mazlum, Deniz - Eyüpgiller, Kemal, Prof. Doğan Kuban'a Armağan, Osmanlı Külliyelerinde Yerleşme Düzeni: Bir Tipoloji Denemesi, Eren Yayıncılık, İstanbul 1996.

AKDAĞ, Mustafa, Türkiye’nin İktisadi ve İçtimai Tarihi, Cem Yayınevi, İstanbul 1995.

AKDEMİR, Sadık, XVIII. Yüzyılın İlk Yarısında Isparta, Isparta Valiliği İl Kültür ve Turizm Müdürlügü Yayınları, Isparta 2008.

ATALAN, Özlem - AREL, Hasan "15. ve 16. Yüzyıllarda Yapılmış Osmanlı Han Yapılarının Mekânsal Analizi”, Turkısh Studıes, Vol.11/2, Ankara 2016.

ATAMAN, Alpaslan, Bir Göz Yapıdan Külliyeye, Mimarlar Tasarım Yayınları, İstanbul 2000.

CAN, Yılmaz. İslam Şehirlerinin Fiziki Yapısı (VII. ve IX. Yüzyıl), Türkiye Diyanet Vakfı Yayınları/169, Ankara 1995.

CANSEVER, Turgut. İslam 'da Şehir ve Mimari, İz Yayıncılık, İstanbul 1997.

CEZAR, Mustafa. Tipik Yapılarıyla Osmanlı Şehirciliğinde Çarşı ve Klasik Dönem İmar Sistemi, Mimar Sinan Üniversitesi Yayını No:9, İstanbul 1985.

ÇETIN, S1dıka "Dönüşüm Sürecinin Tarihi Kent Merkezleri Üzerine Etkileri: Isparta Örneğinde Bir İnceleme”, Erciyes Üniversitesi Fen Bilimleri Enstitüsü Dergisi, 27(2): 185-199 Kayseri 2011.

ÇEVRIMLİ, S.Cevat- Hasan HAŞTEMOĞLU, Geleneksel Çarşılarda Mekânsal Sorunlar ve Çözüm Önerileri, Isparta Üzüm Pazarı Örneği, (Süleyman Demirel Üniversitesi Fenbilimleri Enstitüsü, Yayımlanmamış, Yüksek Lisans Tezi), Isparta 2017.

ÇEVRIMLİ, S.Cevat- Hasan HAŞTEMOĞLU, "Kültürel Sürdürülebilirlik Açısından Isparta Üzüm Pazarı", International Congress of the New Approaches and Technologies for Sustainable Development, September 21-24, Isparta 2017.

\section{History Studies}


DUYMAZ, A. Şevki, "Isparta ve Çevresinde Yer Alan Türk Dönemi Mimari Eserler", Geçmişten Günümüze Isparta, Haz: Hüseyin gül-Songül Boybeyi, Atatürk Kültür Merkezi Yayını:360, Ankara, 2009

DUYMAZ, A. Şevki, "Kentsel Sit Bağlamında Geleneksel Bir Çarşı Örneğinin İrdelenmesi: Isparta Üzüm Pazarı", Xvıl. Ortaçağ Türk Dönemi Kazıları ve Sanat Tarihi Araştırmaları Sетроzуити, 02-05 Ekim İstanbul 2013.

DEMİRGIL, Selçuk. Mazideki Isparta -1, Isparta Belediyesi Yayınları, Isparta 2007.

ERÇETİN, Nuri. Bir Zamanlar Isparta, Erçetin AŞ Yayını, İzmir 2014.

FAROQHI, Suraiya. Osmanlı'da Kentler ve Kentliler, Çev: Neyyir Kalaycıŏglu, Tarih Vakfı Yurt Yayınları, İstanbul 2000.

FOTO REKOR ARŞIVİ, Isparta 2018.

GENÇ, Mehmet. "Osmanlı Esnafı ve Devlet”, Osmanlı Imparatorluğunda Çevre ve Şehir, Çevre ve Şehircilik Bakanlığı Yayınları, İstanbul 2015.

GHARIPOUR, Mohammad. The Bazaar in The Islamic City / Design, Culture and History, The American University in Cairo Pres, Cairo and NewYork 2012.

http://fotokent.blogspot.com/2011/05/isparta-resimleri.html (E.T. 15.09.2018)

ISPARTA VALİLİĞİ, Isparta 1880-1980, İl Özel İdare Müdürlüğü Yayını, Isparta 2001.

ISPARTA TAPU VE KADASTRO MÜDÜRLÜĞÜ ARȘIVİ, Isparta 1959.

INAN, Kenan. "Bedestenlerin Türk Ticari Mimarisindeki Yeri ve Trabzon Bedesteni”, Osmanlı Tarihi Araştırma ve Uygulama Merkezi Dergisi OTAM, 2015, Say1 7.

İNALCIK, Halil. Osmanlı Imparatorluğu Klasik Çağ (1300· 1600), Çev. Ruşen Sezer, YKY, İstanbul 2009.

KÖPRÜLÜ, M.Fuad.Osmanlı İmparatorluğu'nun Kuruluşu, Akçağ Yayınları, Ankara 2009.

KRSTIKKJ, Aleksandra - Koura, Hisako. "Identıfyıng The Signıficance Of Historic Place in Scopje's Old Bazaar", Journal of Architecture and Planning (Transactions of AIJ) · April 2013, Vol. 78, No. 686.

KURAN, Aptullah, Mimar Sinan, Hürriyet Vakfı Yayınları, İstanbul 1986.

KURAN, Timur. Islamic Influences on The Ottoman Guilds, The Great Ottoman-Turkish Civilisation Vol.2 Economy and Society, Ed. Kemal Çiçek, Yeni Türkiye Yayınları, Ankara 2000.

KÜÇÜKKÖMÜRCÜ, Burcu. Geleneksel Türk Osmanlı Çarsı Yapıları ve Günümüzdeki Alışveriş Merkezleri Üzerine Bir İnceleme, (Mimar Sinan Güzel Sanatlar Üniversitesi Fen Bilimleri Enstitüsü, Yüksek Lisans Tezi), İstanbul 2005.

MERÇİL, Erdoğan. Türkiye Selçuklularında Meslekler, Türk Tarih Kurumu Yayınları, Ankara 2000. 
MORTAN, Kenan, - Küçükerman, Önder. Çarşı, Pazar, Ticaret ve Kapalıçarşı, Türkiye İş Bankası Kültür Yayınları, İstanbul 2007.

OLCAYTU, Neşe. Yaşayan Çarşılar, Novartis Kültür Yayınları, No: 17, İstanbul 2005.

ÖZDEŞ, Gündüz. Türk Çarşıları, Tepe Yayınları, Ankara 1998.

SAMİ, Böcüzade Süleyman. Isparta Tarihi, Serenler Yayınevi, İstanbul 1983.

SAKAOĞLU, Necdet. Geleneksel Meslek Örgütlenmeleri ve Anadolu Çarşıları, Osmanlı Çarşıları Atlası, Doğan Dergi Yayıncılık, Bursa 2010.

ŞAHINALP, M. Sait - Günal, Veyis. "Osmanlı Şehircilik Kültüründe Çarşı Sisteminin Lokasyon ve Çarşı İçi Kademelenme Yönünden Mekânsal Analizi”, Millî Folklor, 2012, Y11 24, Say1 93.

ŞATIROĞLU, Ayşen- Okan, Oya. Çarşı-Esnaf Kapalıçarşı, İstanbul Ticaret Odası Yayınları, İstanbul 2010.

TANYELİ, Uğur .Anadolu-Türk Kentinde Fiziksel Yapının Evrim Süreci (11.-15. yy),( İstanbul Teknik Üniversitesi Fen Bilimleri Enstitüsü Basılı Doktora Tezi), İstanbul 1987.

TURGUT, Hulusi. Cumhuriyetten Günümüze Isparta, ABC Basın Ajans1, İstanbul 2000.

UYSAL, Mehmet. "Tarihsel Süreçte Geleneksel Konya Çarşısı İçin Bir Mekansal Analiz”, Milli Folklor Dergisi, 2010, Sayı 86.

YURDALAN, Özcan. Çarşılarla Anadolu Bedestenler, Hanlar, Kapalıçarşılar, Halk Bankası Yayınları, İstanbul 2011.

VAKIFLAR GENEL MÜDÜRLÜĞÜ, Firdevs Bey Cami ve Bedesteni Rölöve Çizimleri, Ankara 1980,

WEBER, Stefan. "The Transformation of an Arab-Ottoman Institution The Suq (Bazar) of Damascus from the 16th to the 20th Century", 7 Centuries of Ottoman Architecture A Supra - National Heritage, Yem Yayınları, Istanbul 1999.

WYCHERLEY, R.E. Antik Çağda Kentler Nasıl Kuruldu?, Çev: Nur Nirven-Nezih Başgelen, Arkeoloji ve Sanat Yayınları, İstanbul 1993. 